\title{
Synthesis of Novel Reactive Polymers Having Oxirane Structure in the Main Chain by Polycondensation of Bis(sulfonium ylide) with Dialdehyde
}

\author{
Toshiyuki OYAma, ${ }^{\dagger}$ Yoshihiro SuZUKI, and Masao TomoI \\ Department of Advanced Materials Chemistry, Faculty of Engineering, Yokohama National University, \\ 79-5 Tokiwadai, Hodogaya-ku, Yokohama 240-8501, Japan
}

(Received March 9, 2004; Accepted June 12, 2004; Published September 15, 2004)

\begin{abstract}
Poly(phenylenevinylene oxide)s (PPVOs) having oxirane groups in the main chain were prepared by the Corey-Chaykovsky reaction between bis(sulfonium ylide)s and dialdehydes. The sulfonium ylide formed in situ from $m$-xylylenebis(dimethylsulfonium perchlorate) by the use of lithium diisopropylamide (LDA) as a base was reacted with terephthalaldehyde to afford $m, p$-PPVO with $M_{\mathrm{n}}=3600$. Oxirane groups in PPVO were successfully reacted with various reagents such as acetic acid, lithium aluminum hydride and $n$-octylamine to give the corresponding ring-opening products. The properties of the ring-opened polymers reflected the structure of the reagents used for the polymer reactions. These results showed that PPVOs are novel reactive polymers whose properties can easily be adjusted by polymer reactions. [DOI 10.1295/polymj.36.737]

KEY WORDS Poly(phenylenevinylene oxide) / Corey-Chaykovsky Reaction / Sulfonium Ylide / Polycondensation / Polymer Reaction / Ring-opening Reaction /
\end{abstract}

Oxirane groups have high reactivity with both nucleophilic and electrophilic reagents due to their ring strain and basicity of the oxygen atoms. Nucleophilic reagents such as amines, ${ }^{1}$ alkoxides, ${ }^{2}$ organometallic reagents (Grignard reagents, ${ }^{3}$ organolithium reagents, ${ }^{4}$ etc.), hydride anion ${ }^{5}$ are known to open oxirane rings. Reaction of oxiranes with triphenylphosphine results in formation of alkenes via Wittig-reaction-like betaine intermediates. ${ }^{6}$ Oxiranes react with various protonic acids to afford the corresponding halohydrins. ${ }^{7}$ Lewis acids such as $\mathrm{BF}_{3} \cdot \mathrm{OEt}_{2}$ cause the pinacol rearrangement of oxiranes to produce aldehydes or ketones. ${ }^{8}$ Ring-opening polymerization of oxiranes can be carried out in both cationic and anionic manners. ${ }^{9}$ Due to the diverse reactivity of oxiranes as mentioned above, the compounds containing oxirane groups have widely utilized for various purposes. Epoxy resins, ones of the most famous oxirane compounds, have been used as structural adhesives, matrix resins for fiber composites, insulating materials and so on because of their good mechanical properties, higher resistance to hydrolytic and chemical degradation and good electrical properties. ${ }^{10}$ Oligomers and polymers having oxirane groups as side chains can be photo-crosslinked in the presence of photo-acid generator and can be used as ultrafast drying of protective coating, printing inks, adhesives, photoresists, etc. ${ }^{11}$ Thus, a polymer having oxirane groups in the main chain is expected to react with various reagents and to be used as a new reactive polymer.

There are three principal methods for preparing oxirane compounds; 1 . epoxidation of alkenes with peroxides, ${ }^{12} 2$. dehalogenation of halohydrins in the presence of bases, ${ }^{13}$ and 3. condensation of carbonyl compounds with ylide-like reagents such as sulfurylides (the Corey-Chaykovsky reaction), ${ }^{14}$ enolate anions of $\alpha$-haloesters (the Darzens reaction), ${ }^{15}$ and diazoalkanes. ${ }^{16}$ Though there are many examples for synthesis of oxiranes by the first two methods, polycondensation using the third method as an elementary reaction would be most suitable for quantitative introduction of oxirane groups into the polymer main chain, because the oxirane groups are inevitably formed in every condensation step. Sulfur ylides would be most stable among ylide-like reagents that can be used for oxirane formation, and hence they are easy to handle. Thus, in this paper, we study synthesis of poly(phenylenevinylene oxide)s (PPVOs) by polycondensation of aromatic dialdehydes with sulfonium ylides prepared in situ from xylylenebis(dimethylsulfonium) salts and appropriate bases. PPVO can be regarded as an alternating copolymer between phenylene unit and oxirane group and is expected to react with a wide variety of reagents. Polymer reactions of PPVO with various nucleophilic and electrophilic reagents and the properties of the resulting polymers are also examined.

${ }^{\dagger}$ To whom correspondence should be addressed (E-mail: oyama1@ynu.ac.jp). 


\section{EXPERIMENTAL}

\section{General}

${ }^{1} \mathrm{H}$ and ${ }^{13} \mathrm{C}$ NMR spectra were obtained with a JEOL JNM-EX270 spectrometer $\left(270 \mathrm{MHz}\right.$ for $\left.{ }^{1} \mathrm{H}\right)$ in DMSO- $d_{6}$ by the use of tetramethylsilane as an internal standard. IR spectra were recorded on a PerkinElmer Spectrum One FT-IR spectrometer. Gel permeation chromatographic analyses (GPC) by using tetrahydrofuran as an eluent were carried out on a Tosoh GPC-8020 with RI-8021 (Tosoh TSKgel $\mathrm{GMH}_{\mathrm{XL}}-\mathrm{H}+\mathrm{GMH}_{\mathrm{HR}}-\mathrm{H}$ columns, eluting rate 1.0 $\mathrm{mL} / \mathrm{min}$ ) after calibration with standard polystyrenes. DSC analyses were carried out on a Shimadzu DSC60 at heating rate of $10^{\circ} \mathrm{C} / \mathrm{min}$. The onsets of $T_{\mathrm{g}}$ peaks in the thermograms at the second heating scans were adopted as the values of the glass transition temperatures.

Unless otherwise noted, the materials were obtained from commercial sources. Chloroform, dimethyl sulfoxide (DMSO) and $\mathrm{N}, \mathrm{N}$-dimethylformamide (DMF) were distilled under nitrogen from $\mathrm{CaH}_{2}$. THF, toluene and 1,4-dioxane were distilled from sodium diphenylketyl.

\section{Synthesis of p-Xylylenebis(dimethylsulfonium perchlo- rate) 1}

p-Xylylene dibromide $(2.00 \mathrm{~g}, 7.59 \mathrm{mmol})$, dimethyl sulfide $(1.89 \mathrm{~g}, 30.4 \mathrm{mmol})$ and DMSO $(15 \mathrm{~mL})$ were added into a $50 \mathrm{~mL}$ two-necked flask. Silver perchlorate $(3.15 \mathrm{~g}, 15.2 \mathrm{mmol})$ was added into the solution, and the mixture was stirred for $18 \mathrm{~h}$ at room temperature. A pale green precipitate formed during the reaction was filtered, and the resulting filtrate was poured into a large amount of diethyl ether to give a colorless liquid at the bottom of the vessel. The supernatant (diethyl ether) was removed by decantation and the remained liquid was added dropwise into a large amount of ethanol. The obtained white precipitate was isolated by suction filtration and recrystallized from water to afford the compound $\mathbf{1}$ in $90 \%$ yield. ${ }^{1} \mathrm{H}$ NMR $\quad(\delta, \quad$ ppm $) \quad 2.72 \quad\left(-\mathrm{CH}_{3}, \quad \mathrm{~s}, \quad 12 \mathrm{H}\right), \quad 4.58$ $\left(-\mathrm{CH}_{2}-, \mathrm{s}, 4 \mathrm{H}\right), 7.47$ (Ar-H, s, 4H).

Synthesis of m-Xylylenebis(dimethylsulfonium perchlorate) 2

The title compound was prepared by reacting $m$ xylylene dibromide $(10.2 \mathrm{~g}, 38.5 \mathrm{mmol})$ with dimethyl sulfide $(9.56 \mathrm{~g}, 153.9 \mathrm{mmol})$ in the presence of silver perchlorate $(16.0 \mathrm{~g}, 77.1 \mathrm{mmol})$ in DMSO, according to the procedure for the synthesis of $\mathbf{1}$. The sulfonium salt 2 was obtained in $88 \%$ yield. ${ }^{1} \mathrm{H}$ NMR $(\delta$, ppm) $2.81\left(-\mathrm{CH}_{3}, \mathrm{~s}, 12 \mathrm{H}\right), 4.66\left(-\mathrm{CH}_{2}-, \mathrm{s}, 4 \mathrm{H}\right), 7.45-7.60$ $(\mathrm{Ar}-\mathrm{H}, \mathrm{m}, 4 \mathrm{H})$.
Synthesis of Poly[(m-phenylenevinylene oxide)-co(p-phenylenevinylene oxide)] (m,p-PPVO) by the Use of Methylsulfinyl Carbanion (Dimsyl Anion) as a Base

In a $200 \mathrm{~mL}$ three-necked flask equipped with a reflux condenser, a thermometer and a dropping funnel were placed sodium hydride $(0.33 \mathrm{~g}, 13.8 \mathrm{mmol})$, THF $(49 \mathrm{~mL})$ and DMSO $(14 \mathrm{~mL})$. After stirring at $60^{\circ} \mathrm{C}$ for $1 \mathrm{~h}$, the system was ice-cooled and a mixture of $2(2.95 \mathrm{~g}, 6.90 \mathrm{mmol})$ and terephthalaldehyde $(0.93 \mathrm{~g}, 6.90 \mathrm{mmol})$ in DMSO $(21 \mathrm{~mL})$ was added dropwise for $10 \mathrm{~min}$. The mixture was stirred at $0^{\circ} \mathrm{C}$ for $1 \mathrm{~h}$ and at room temperature for $6 \mathrm{~h}$ followed by evaporation of THF in vacuo. The resultant solution was poured into $500 \mathrm{~mL}$ of water to give a white precipitate, and the precipitate was isolated by suction filtration. The obtained solid was reprecipitated by $\mathrm{THF} /$ methanol and THF/ $n$-hexane followed by vacuum drying at $60^{\circ} \mathrm{C}$ for $17 \mathrm{~h}$ to afford $m, p$-PPVO as a white solid in $62 \%$ yield. ${ }^{1} \mathrm{H}$ NMR $(\delta, \mathrm{ppm}) 4.12$ (Ar$\mathrm{C}-\mathrm{H}, \mathrm{br}, 4 \mathrm{H}), 7.20-7.48$ (Ar-H, br, 8H). ${ }^{13} \mathrm{C}$ NMR $(\delta$, ppm) 62.7, 122.0, 122.5, 125.0, 125.4, 125.7, 128.8, 137.1, 137.4. IR (KBr): 835 (oxirane ring) $\mathrm{cm}^{-1}$.

\section{Synthesis of m,p-PPVO by the Use of Lithium Diiso- propylamide (LDA) as a Base}

In a $100 \mathrm{~mL}$ three-necked flask equipped with a thermometer and a dropping funnel were placed diisopropylamine $(1.30 \mathrm{~g}, 12.8 \mathrm{mmol})$ and THF $(25 \mathrm{~mL})$, and the solution was cooled to $0{ }^{\circ} \mathrm{C}$. $n$-Butyllithium $(1.6 \mathrm{M}$ in hexane, $8.0 \mathrm{~mL}, 12.8 \mathrm{mmol})$ was added dropwise from syringe and the system was stirred for $15 \mathrm{~min}$. A mixture of $2(2.74 \mathrm{~g}, 6.40 \mathrm{mmol})$ and terephthalaldehyde $(0.86 \mathrm{~g}, 6.40 \mathrm{mmol})$ in DMSO $(8.0 \mathrm{~mL})$ was then added dropwise for $10 \mathrm{~min}$. The mixture was stirred at $0{ }^{\circ} \mathrm{C}$ for $1 \mathrm{~h}$ and at room temperature for $6 \mathrm{~h}$ followed by evaporation of THF in $v a$ сио. Isolation and purification described as above afforded $m, p$-PPVO as a white solid in $86 \%$ yield.

Ring-opening Reaction of m,p-PPVO with Acetic Acid $m$,p-PPVO $(0.10 \mathrm{~g}, 0.85 \mathrm{mmol}$ of oxirane), acetic acid $(0.98 \mathrm{~mL}, 17.2 \mathrm{mmol})$ and chloroform $(3 \mathrm{~mL})$ were placed in a $50 \mathrm{~mL}$ three-necked flask equipped with a reflux condenser. The mixture was refluxed for $5 \mathrm{~d}$ and the resulting solution was poured into a large amount of diethyl ether to give a precipitate. Reprecipitation of the obtained solid from THF/diethyl ether gave the polymer with $\mathrm{OH}$ and $\mathrm{CH}_{3} \mathrm{COO}$ groups $(\mathbf{3})$ as a pale yellow solid. ${ }^{1} \mathrm{H} \operatorname{NMR}(\delta, \mathrm{ppm})$ $1.98\left(-\mathrm{CH}_{3}\right.$, br, $\left.6 \mathrm{H}\right), 4.77(-\mathrm{C} \underline{\mathrm{H}}-\mathrm{OH}$, br, $2 \mathrm{H}), 5.68$ $(-\mathrm{CH}-\mathrm{OC}(\mathrm{O})-$, br, 2H), $7.04(\mathrm{Ar}-\mathrm{H}$, br, 8H). IR $(\mathrm{KBr}): 3451(v \mathrm{OH}), 1740(v \mathrm{C}=\mathrm{O}) \mathrm{cm}^{-1}$. 
Ring-opening Reaction of m,p-PPVO with Lithium Aluminum Hydride (LAH)

To a suspension of LAH $(0.10 \mathrm{~g}, 2.52 \mathrm{mmol})$ in THF $(2.0 \mathrm{~mL})$ was added dropwise $m, p$-PPVO $(0.15 \mathrm{~g}, 1.27 \mathrm{mmol}$ of oxirane $)$ in THF $(3.0 \mathrm{~mL})$ at $-78^{\circ} \mathrm{C}$. The mixture was gradually warmed to ambient temperature and stirred for $18 \mathrm{~h}$ followed by the addition of ethyl acetate to consume excess LAH. After adjusting $\mathrm{pH}$ of the system to 5 by $1.0 \mathrm{M} \mathrm{NH}_{4} \mathrm{Cl}$ aq., THF was evaporated in vacuo and the mixture was filtered. The obtained solid was dissolved in methanol and, after filtration, the solution was added dropwise to water. Isolation of the precipitate by filtration and vacuum drying afforded the polymer having $\mathrm{OH}$ groups (4) as a white solid. ${ }^{1} \mathrm{H}$ NMR $(\delta, \mathrm{ppm})$ $2.81\left(-\mathrm{CH}_{2}-\right.$, br, $\left.4 \mathrm{H}\right), 4.68(-\mathrm{CH}-\mathrm{OH}, \mathrm{br}, 2 \mathrm{H}), 5.17$ $(-\mathrm{OH}$, br, 2H), 7.14 (Ar-H, m(br), 8H). IR (KBr): $3401(v \mathrm{OH}) \mathrm{cm}^{-1}$.

Ring-opening Reaction of m,p-PPVO with n-Octylamine

To a solution of $m, p$-PPVO $(0.19 \mathrm{~g}, 1.61 \mathrm{mmol}$ of oxirane) in DMSO $(5.0 \mathrm{~mL})$ was added $n$-octylamine $(4.14 \mathrm{~g}, 32.1 \mathrm{mmol})$ and the solution was heated with stirring at $150^{\circ} \mathrm{C}$ for $20 \mathrm{~h}$. After evaporating excess $n$-octylamine in vacuo, the solution was poured into a large amount of water and the resulting precipitate was isolated by filtration. The obtained solid was purified by successive reprecipitations with $\mathrm{THF} / \mathrm{H}_{2} \mathrm{O}-$ $\mathrm{CH}_{3} \mathrm{OH}$ (1:1) and THF/hexane and by vacuum drying $\left(60^{\circ} \mathrm{C}, 18 \mathrm{~h}\right)$ to give the polymer with $\mathrm{OH}$ and $n$ $\mathrm{C}_{8} \mathrm{H}_{17} \mathrm{NH}$ groups (5) as a pale yellow solid. ${ }^{1} \mathrm{H}$ NMR $(\delta, \mathrm{ppm}) 0.87\left(-\mathrm{CH}_{3}, \mathrm{br}, 6 \mathrm{H}\right), 1.22\left(-\mathrm{CH}_{2}-, \mathrm{br}, 24 \mathrm{H}\right)$, $2.30\left(-\mathrm{NH}-\mathrm{CH}_{2}-\right.$, br, $\left.2 \mathrm{H}\right), 3.71(-\mathrm{C} \underline{-}-\mathrm{NH}-$, br, $2 \mathrm{H})$, 4.68 (-CH-OH, br, 2H) 7.07 (Ar-H, br, 8H). IR $(\mathrm{KBr}): 3326(v \mathrm{O}-\mathrm{H}), 2925(v \mathrm{C}-\mathrm{H}) \mathrm{cm}^{-1}$.

\section{Ring-opening Reaction of m,p-PPVO with Sodium 2-Methoxyethoxide}

In a $200 \mathrm{~mL}$ two-necked flask equipped with a reflux condenser were placed sodium hydride $(0.60 \mathrm{~g}$, $25.0 \mathrm{mmol})$ and 2-methoxyethanol (77.2 g, $1.01 \mathrm{~mol})$, and the mixture was stirred until evolution of hydrogen ceased and the system became clear. $m, p$-PPVO $(0.185 \mathrm{~g}, 1.56 \mathrm{mmol}$ of oxirane) was added to the mixture and stirred at $100^{\circ} \mathrm{C}$ for $7 \mathrm{~d}$. The resulting mix- ture was concentrated in vacuo and then poured into a large amount of water. The obtained precipitate was isolated by suction filtration, washed with methanol and dried in vacuo to afford the polymer containing $\mathrm{OH}$ and $\mathrm{OCH}_{2} \mathrm{CH}_{2} \mathrm{OCH}_{3}$ groups (6) as a pale brown solid. IR (KBr): 3413 ( $v$ O-H), 1087 (v $\left.-\mathrm{CH}_{2}-\mathrm{O}-\mathrm{CH}_{2}-\right) \mathrm{cm}^{-1}$.

The Pinacol Rearrangement of m,p-PPVO with $\mathrm{BF}_{3} \cdot \mathrm{OEt}_{2}$

To a solution of $m, p$-PPVO $(0.11 \mathrm{~g}, 0.93 \mathrm{mmol}$ of oxirane) in chloroform $(3.0 \mathrm{~mL})$ was added $\mathrm{BF}_{3} \cdot \mathrm{OEt}_{2}$ $(0.064 \mathrm{~g}, 0.45 \mathrm{mmol})$ at $0{ }^{\circ} \mathrm{C}$. After $1 \mathrm{~min}$, the reaction was stopped by addition of water $(30 \mathrm{~mL})$ and the resultant precipitate was isolated by suction filtration. Washing the solid with water and vacuum drying $\left(60{ }^{\circ} \mathrm{C}, 18 \mathrm{~h}\right)$ gave the polymer with $\mathrm{CHO}$ groups $(7)$ as a pale brown solid. IR (KBr): $1720(v \mathrm{C}=\mathrm{O}$ of aldehyde) $\mathrm{cm}^{-1}$.

\section{RESULTS AND DISCUSSION}

\section{Synthesis of Poly(phenylenevinylene oxide)s}

The reactions of sulfonium ylides with aldehydes, well known as the Corey-Chaykovsky reaction, ${ }^{14}$ are widely used for construction of oxirane structures. In this study, polycondensation of bis(dimethylsulfonium) xylylides with dialdehydes was carried out as a novel method for synthesis of polymers having oxirane groups in the main chain.

An attempt to synthesize poly ( $p$-phenylenevinylene oxide) ( $p$-PPVO) from a ylide of $p$-xylylenebis(dimethylsulfonium perchlorate) $\mathbf{1}$ and terephthalaldehyde afforded a yellow solid having an absorption at $824 \mathrm{~cm}^{-1}$ derived from oxirane ring in the IR spectrum. However, this polymer was insoluble in any solvent and further identification was impossible. Therefore, synthesis of poly $(m$-phenylenevinylene oxide) ( $m$-PPVO) from a ylide of $m$-xylylenebis(dimethylsulfonium perchlorate) $\mathbf{2}$ and isophthalaldehyde was examined to obtain a soluble polymer by introducing $m$-phenylene unit in the main chain (Scheme 1). Results when methylsulfinyl carbanion (dimsyl anion) ${ }^{17}$ was used as a base for generating the ylide are shown in Table I. Use of a large amount of DMSO as a solvent for the monomers resulted in low-molecular-

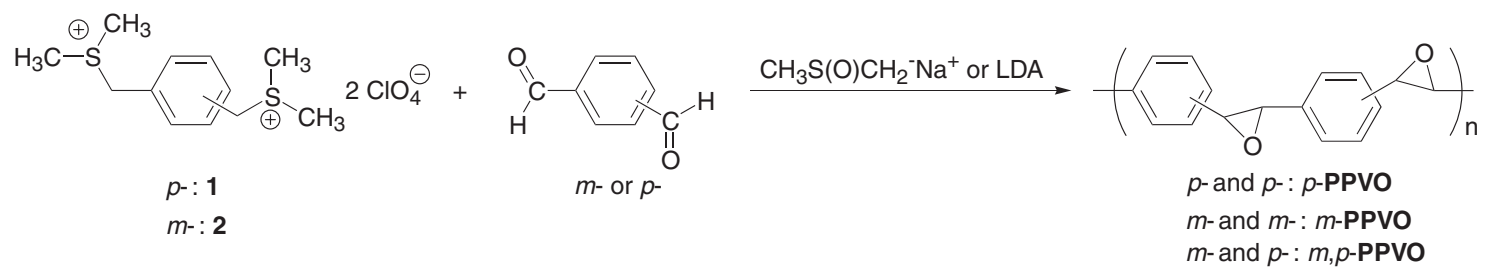

Scheme 1. 
Table I. Synthesis of $m$-PPVO using dimsyl anion as a base ${ }^{\mathrm{a}}$

\begin{tabular}{|c|c|c|c|c|c|c|c|c|}
\hline \multirow[b]{2}{*}{ Run } & \multicolumn{2}{|c|}{ Preparation of dimsyl anion } & \multicolumn{3}{|c|}{ Monomer solution } & \multirow[b]{2}{*}{$\begin{array}{l}\text { Yield } \\
(\%)\end{array}$} & \multirow[b]{2}{*}{$M_{\mathrm{n}}^{\mathrm{b}}$} & \multirow[b]{2}{*}{$M_{\mathrm{w}} / M_{\mathrm{n}}^{\mathrm{b}}$} \\
\hline & $\begin{array}{c}\mathrm{NaH} \\
(\mathrm{mmol})\end{array}$ & $\begin{array}{l}\text { DMSO } \\
(\mathrm{mL})\end{array}$ & $\begin{array}{c}2 \\
(\mathrm{mmol})\end{array}$ & $\begin{array}{l}\text { Isophthal- } \\
\text { aldehyde } \\
(\mathrm{mmol})\end{array}$ & $\begin{array}{l}\text { DMSO } \\
(\mathrm{mL})\end{array}$ & & & \\
\hline 1 & 3.8 & 3.7 & 1.9 & 1.9 & 4.0 & 60 & 1900 & 1.8 \\
\hline 2 & 3.9 & 3.7 & 1.9 & 1.9 & 1.0 & 54 & 2200 & 1.8 \\
\hline 3 & 4.0 & 2.0 & 2.0 & 2.0 & 1.0 & 40 & 2200 & 2.1 \\
\hline 4 & 4.0 & 1.0 & 2.0 & 2.0 & 1.0 & 33 & 2400 & 1.7 \\
\hline
\end{tabular}

${ }^{\mathrm{a}}$ Reaction conditions: r.t. $/ 7 \mathrm{~h}{ }^{\mathrm{b}}$ Determined by GPC. Eluent: THF. Polystyrene was used as the standard for calibration.

Table II. Synthesis of $m$-PPVO using LDA as a base ${ }^{\text {a }}$

\begin{tabular}{cccccccr}
\hline Run & $\begin{array}{c}\mathbf{2} \\
(\mathrm{mmol})\end{array}$ & $\begin{array}{c}\text { Isophthal- } \\
\text { aldehyde } \\
(\mathrm{mmol})\end{array}$ & $\begin{array}{c}\text { LDA } \\
(\mathrm{mmol})\end{array}$ & $\begin{array}{c}\text { DMSO }+ \text { THF } \\
(\mathrm{mL})\end{array}$ & $\begin{array}{c}\text { Yield } \\
(\%)\end{array}$ & $M_{\mathrm{n}} \mathrm{b}^{\mathrm{b}}$ & $M_{\mathrm{w}} / M_{\mathrm{n}}{ }^{\mathrm{b}}$ \\
\hline 1 & 2.0 & 2.0 & 4.0 & $1.0+3.0$ & 39 & 1900 & 1.4 \\
2 & 2.0 & 2.0 & 4.0 & $2.0+2.0$ & 76 & 2200 & 1.6 \\
3 & 2.0 & 2.0 & 4.0 & $3.0+3.0$ & 76 & 2100 & 1.5 \\
4 & 2.0 & 2.0 & 4.4 & $3.0+3.0$ & 78 & 2000 & 2.1 \\
\hline
\end{tabular}

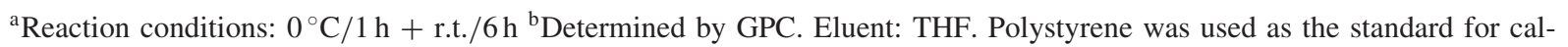
ibration.

Table III. Synthesis of $m, p$-PPVOa

\begin{tabular}{ccccccccc}
\hline Run & $\begin{array}{c}\mathbf{2} \\
(\mathrm{mmol})\end{array}$ & $\begin{array}{c}\text { Terephthal- } \\
\text { aldehyde } \\
(\mathrm{mmol})\end{array}$ & $\begin{array}{c}\text { Dimsyl anion } \\
(\mathrm{mmol})\end{array}$ & $\begin{array}{c}\text { LDA } \\
(\mathrm{mmol})\end{array}$ & $\begin{array}{c}\text { Solvent } \\
(\mathrm{mL})\end{array}$ & $\begin{array}{c}\text { Yield } \\
(\%)\end{array}$ & $M_{\mathrm{n}}{ }^{\mathrm{d}}$ & $M_{\mathrm{w}} / M_{\mathrm{n}}{ }^{\mathrm{d}}$ \\
\hline 1 & 6.90 & 6.90 & 13.8 & - & $84^{\mathrm{b}}$ & 62 & 3100 & 2.8 \\
2 & 0.70 & 0.70 & 1.76 & - & $8.4^{\mathrm{b}}$ & 63 & 1600 & 2.4 \\
3 & 0.70 & 0.84 & 1.76 & - & $8.4^{\mathrm{b}}$ & 28 & 1900 & 2.3 \\
4 & 6.40 & 6.40 & - & 12.8 & $33^{\mathrm{c}}$ & 86 & 3600 & 2.7 \\
\hline
\end{tabular}

${ }^{\mathrm{a}}$ Reaction conditions: $0{ }^{\circ} \mathrm{C} / 1 \mathrm{~h}+$ r.t. $/ 6 \mathrm{~h}{ }^{\mathrm{b}} \mathrm{DMSO} / \mathrm{THF}=5 / 7(\mathrm{v} / \mathrm{v})^{\mathrm{c}} \mathrm{DMSO} / \mathrm{THF}=8 / 25(\mathrm{v} / \mathrm{v}){ }^{\mathrm{d}}$ Determined by GPC. Eluent: THF. Polystyrene was used as the standard for calibration.

weight $m$-PPVO $\left(M_{\mathrm{n}}=1900\right)$ (run 1). Molecular weight of $m$-PPVO slightly increased as the amount of DMSO decreased (runs 2-4) and $m$-PPVO with $M_{\mathrm{n}}=2400$ was obtained in run 4. However, the yield of the polymers decreased with decreasing amount of DMSO probably due to heterogeneity of the system during the polymerization. Use of lithium diisopropylamide (LDA) as a base for ylide formation was also examined. The results for preparation of $m$-PPVO in the presence of LDA as a base are summarized in Table II. A small amount of DMSO used as a solvent made the reaction system heterogeneous, which resulted in the lower yield and molecular weight (run 1). With increase in DMSO, the yield of $\mathrm{m}$ PPVO was improved because the reactions proceeded homogeneously (runs 2-3). As shown in run 4, addition of excess LDA did not change the yield and the molecular weight, and this result indicates that reactivity of LDA with bissulfonium salt is sufficiently high. $m$-PPVO was soluble in DMSO, DMF, THF, 1,4-dioxane, chloroform and dichloromethane, and
$m$-PPVO in run 2 of Table II showed the glass transition temperature $\left(T_{\mathrm{g}}\right)$ at $118^{\circ} \mathrm{C}$. An absorption derived from oxirane rings was observed at $864 \mathrm{~cm}^{-1}$ in the IR spectrum.

Synthesis of $m, p$-PPVO by the reaction of the ylide derived from 2 with terephthalaldehyde was examined in order to obtain the polymer with higher molecular weight in higher yield (Scheme 1). Table III summarizes the results of polycondensation using dimsyl anion as a base for ylide formation. Use of equivalent amounts of sulfonium salt, base and aldehyde gave $m, p$-PPVO with $M_{\mathrm{n}}=3100$ in $62 \%$ yield as shown in run 1. The yield and/or the molecular weight decreased when the excess amount of base or aldehyde was added (runs 2-3). Preparation of the polymer by the stoichiometric amounts of bissulfonium salt, dialdehyde and LDA resulted in the highest molecular weight $\left(M_{\mathrm{n}}=3600\right)$ and the best yield $(86 \%)$ (run 4), probably because LDA does not work as a nucleophile though dimsyl anion would cause nucleophilic substitution reaction with the bissulfonium 


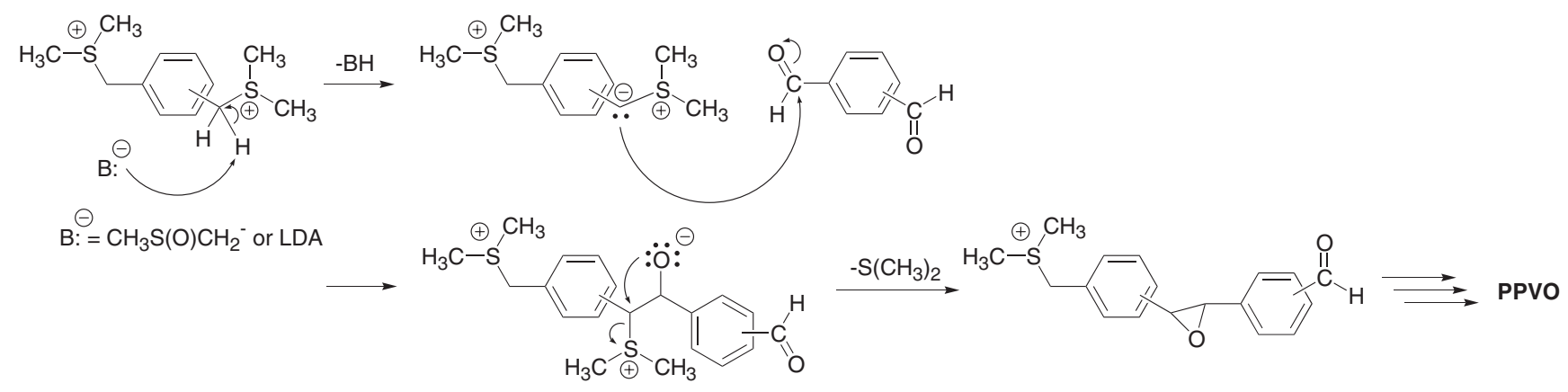

Scheme 2.

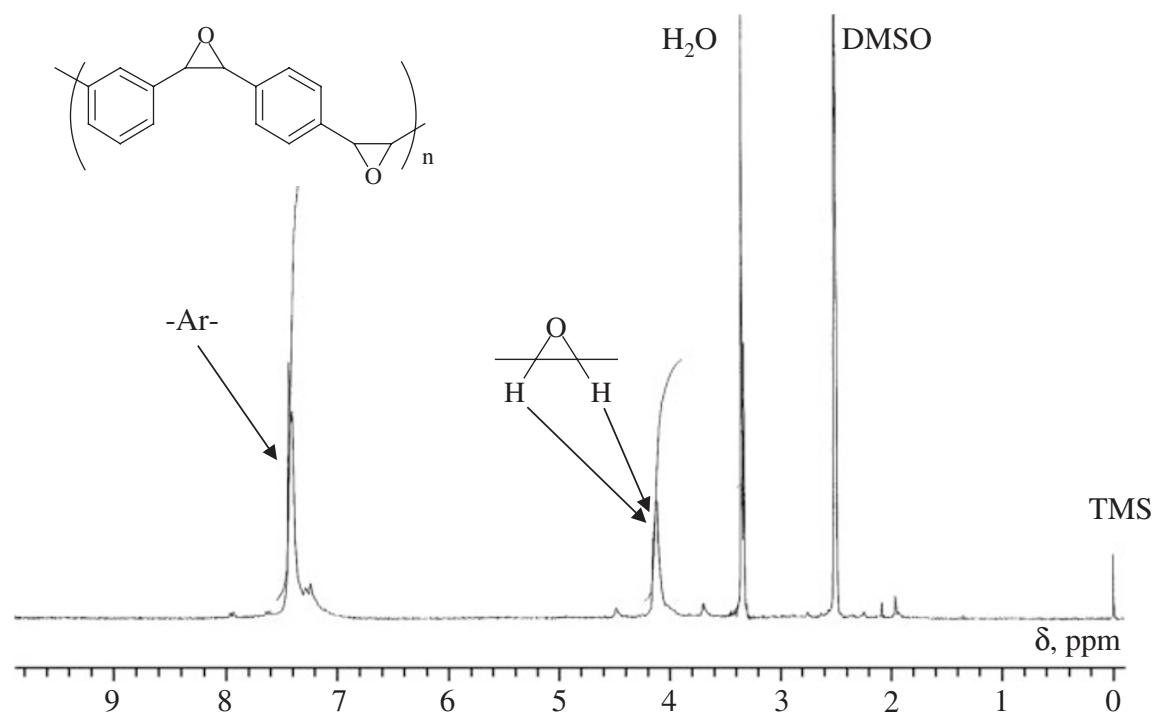

Figure 1. ${ }^{1} \mathrm{H}$ NMR spectrum of $m, p$-PPVO in DMSO- $d_{6}$.

salt 2. The polymerization mechanism is shown in Scheme 2. A base abstracts a hydrogen at a benzylic carbon in a sulfonium salt to give a sulfonium ylide, and the ylide attacks a carbonyl carbon of an aldehyde. Elimination of dimethyl sulfide by the attack of $\mathrm{O}^{-}$in the intermediate affords an oxirane ring. Repetition of these reactions results in the formation of polymers. $m, p$-PPVO showed identical solubility with $m$-PPVO, but $T_{\mathrm{g}}$ of $m, p$-PPVO was not observed in DSC measurements. An exothermic peak observed at $180^{\circ} \mathrm{C}$ in the DSC profile would be derived from the reaction of oxirane rings because the sample became insoluble after DSC measurements. The ${ }^{1} \mathrm{H}$ and ${ }^{13} \mathrm{C}$ NMR spectra of $m, p$-PPVO are shown in Figure 1 and 2, respectively. A peak assigned to protons in oxirane rings was observed at $4.12 \mathrm{ppm}$ in the ${ }^{1} \mathrm{H}$ NMR spectrum. In the ${ }^{13} \mathrm{C}$ NMR spectrum, carbons in oxirane rings showed one peak at $62.7 \mathrm{ppm}$. These results suggest that the oxirane rings in $m, p$ PPVO have a single configuration, and taking into account the literatures reporting formation of transproducts by reactions of sulfur ylides with alde- hydes, ${ }^{14 c, d}$ the oxiranes in $m, p$-PPVO will have trans configuration. An absorption derived from oxirane rings was observed at $835 \mathrm{~cm}^{-1}$ in the IR spectrum of $m, p$-PPVO (Figure 3).

\section{Polymer Reactions of m,p-PPVO}

PPVOs can be regarded as a novel kind of reactive polymers owing to the oxirane rings in the main chain, and therefore, properties of PPVOs can be adjusted by reacting various molecules with the oxirane moieties in the polymers. Here, reactions of $m, p$-PPVO with acetic acid, ${ }^{18}$ lithium aluminum hydride (LAH) ${ }^{5} n$ octylamine, ${ }^{1}$ sodium 2-methoxyethoxide ${ }^{2}$ and $\mathrm{BF}_{3}$. $\mathrm{OEt}_{2}{ }^{8}$ were examined (Scheme 3). Though all structural formulae are described as head-to-tail structures in Scheme 3, ratios between head-to-tail and headto-head could not be determined from the ${ }^{1} \mathrm{H}$ NMR spectra.

Table IV summarizes the results for the polymer reactions. The reaction of $m, p$-PPVO with 1.2 equivalents of acetic acid did not open the oxirane ring at all (run 1). However, as shown in run 2, the oxirane 


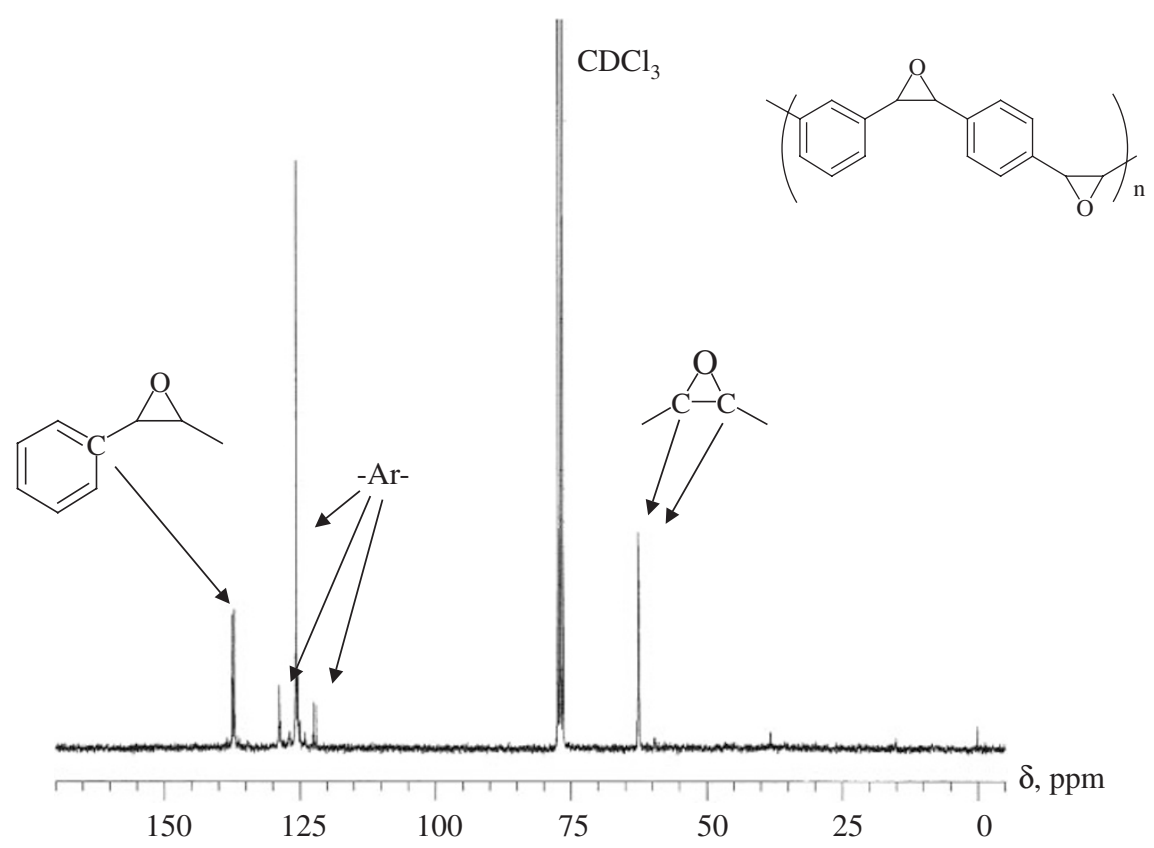

Figure 2. ${ }^{13} \mathrm{C}$ NMR spectrum of $m, p$-PPVO in $\mathrm{CDCl}_{3}$.

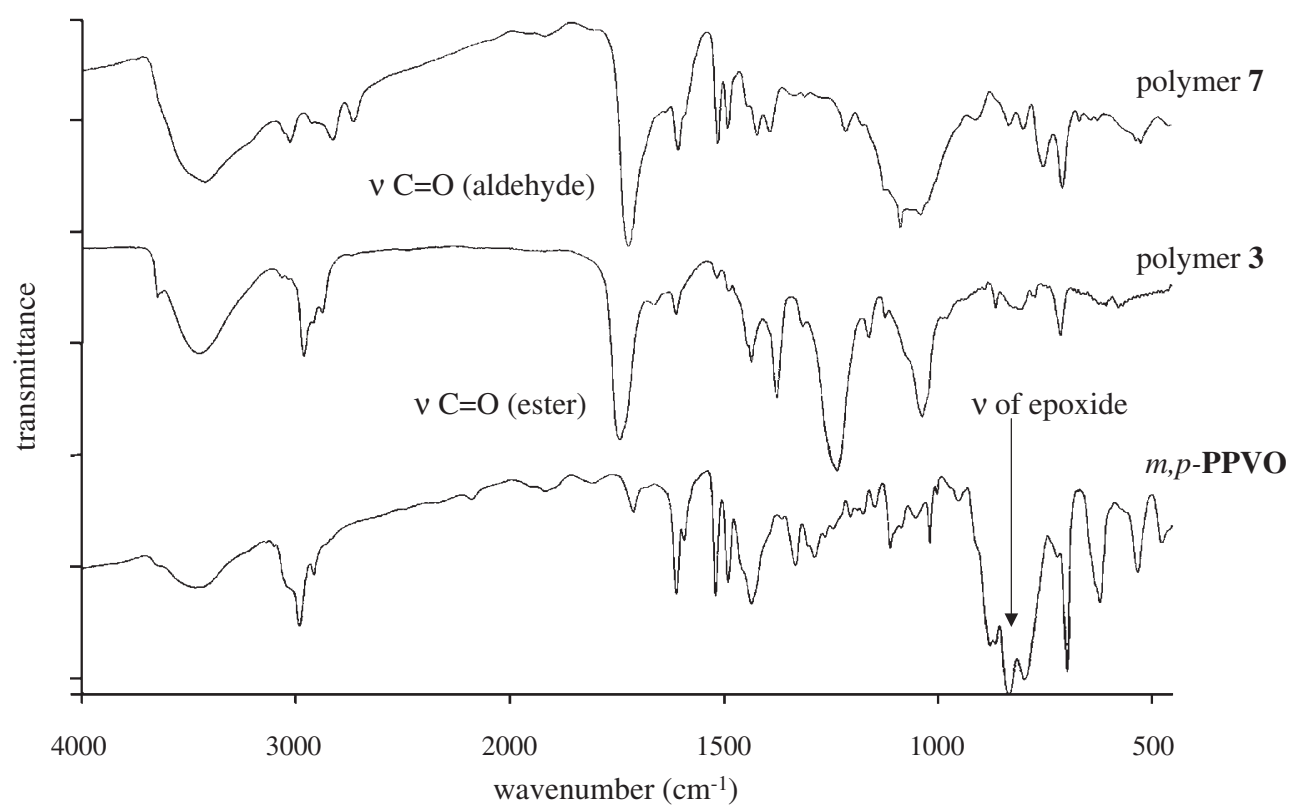

Figure 3. IR spectra of $m, p$-PPVO, polymer 3 and polymer 7 .

rings were completely reacted to afford the polymer $\mathbf{3}$ with $\mathrm{OH}$ and $\mathrm{CH}_{3} \mathrm{COO}$ groups when 20 equivalents of acetic acid were used. $M_{\mathrm{n}}$ of $\mathbf{3}$ increased after the polymer reaction and no main-chain scission was observed. Figure 4 shows the ${ }^{1} \mathrm{H}$ NMR spectrum of $\mathbf{3}$, and no peak was observed around $4.1 \mathrm{ppm}$ (protons of oxirane rings, see Figure 1). The integral ratio of the peak assignable to $-\mathrm{C} \underline{\mathrm{H}}\left(\mathrm{OC}(\mathrm{O}) \mathrm{CH}_{3}\right)-(5.68 \mathrm{ppm})$ was larger than that assigned to $-\mathrm{CH}(\mathrm{OH})$ $(4.77 \mathrm{ppm})$ probably because some $\mathrm{OH}$ groups would be esterified during the ring-opening reaction. ${ }^{18}$ In the IR spectrum of 3 (Figure 3), the absorption derived from oxirane rings at $835 \mathrm{~cm}^{-1}$ was not observed and a new absorption assigned to stretching vibration of ester $\mathrm{C}=\mathrm{O}$ was observed. The polymer 3 showed $T_{\mathrm{g}}$ at $141{ }^{\circ} \mathrm{C}$ in DSC measurements.

When $m, p$-PPVO was reacted with eight equivalents of LAH in refluxing THF for $17 \mathrm{~h}$, the peak and the absorption assigned to oxirane rings were disappeared in the ${ }^{1} \mathrm{H}$ NMR and IR spectra, respectively, and these results suggest that the polymer 4 with $\mathrm{OH}$ groups was successfully obtained (run 3 , Scheme 3 ). Though slight decrease in molecular weight was observed after the polymer reaction, main-chain scission 

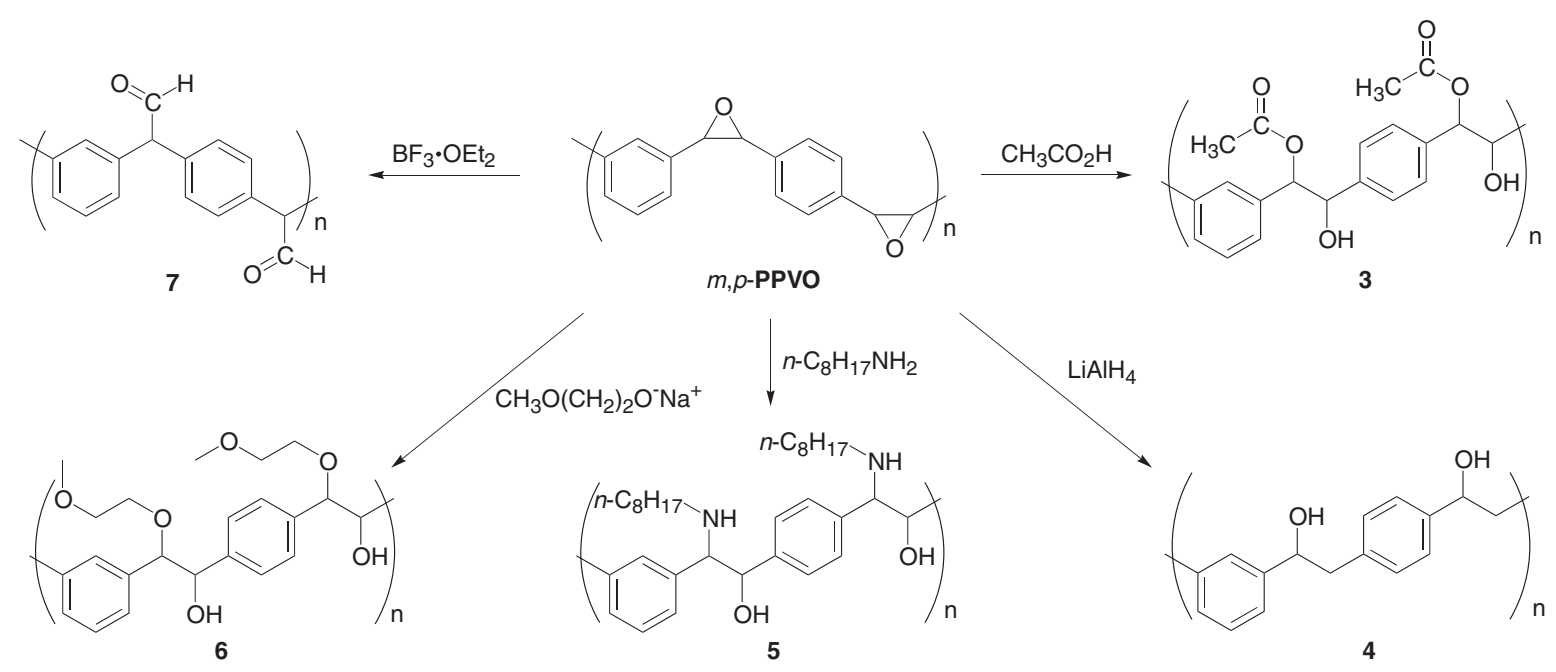

Scheme 3.

Table IV. Polymer reactions of $m, p$-PPVO with various reagents

\begin{tabular}{|c|c|c|c|c|c|c|c|c|c|c|}
\hline \multirow{2}{*}{ Run } & \multicolumn{2}{|c|}{$m, p$-PPVO } & \multirow{2}{*}{ Reagent [eq.] } & \multirow{2}{*}{ Solvent } & \multirow{2}{*}{$\begin{array}{l}\text { Condition } \\
\left({ }^{\circ} \mathrm{C} / \text { time }\right)\end{array}$} & \multirow{2}{*}{$\begin{array}{c}\text { Conv. } \\
(\%)\end{array}$} & \multicolumn{4}{|c|}{ Obtained polymer } \\
\hline & $M_{\mathrm{n}}{ }^{\mathrm{a}}$ & $M_{\mathrm{w}} / M_{\mathrm{n}}^{\mathrm{a}}$ & & & & & & $M_{\mathrm{n}}{ }^{\mathrm{a}}$ & $M_{\mathrm{w}} / M_{\mathrm{n}}{ }^{\mathrm{a}}$ & $T_{\mathrm{g}}\left({ }^{\circ} \mathrm{C}\right)^{\mathrm{b}}$ \\
\hline 1 & 2400 & 2.5 & Acetic acid [1.2] & 1,4-Dioxane & reflux $/ 15 \mathrm{~h}$ & $0^{c}$ & & 2400 & 2.4 & - \\
\hline 2 & 2400 & 2.5 & Acetic acid [20] & $\mathrm{CHCl}_{3}$ & reflux $/ 5 \mathrm{~d}$ & $100^{\mathrm{c}}$ & 3 & 3300 & 2.2 & 141 \\
\hline 3 & 2200 & 1.9 & $\mathrm{LiAlH}_{4}[8]$ & THF & reflux $/ 17 \mathrm{~h}$ & $100^{\mathrm{c}}$ & 4 & 2000 & 1.5 & 81 \\
\hline 4 & 3100 & 2.8 & $n$-Octylamine [20] & 1,4-Dioxane & reflux $/ 15 \mathrm{~h}$ & $17^{\mathrm{c}}$ & & - & - & - \\
\hline 5 & 3100 & 2.8 & $n$-Octylamine [20] & DMSO & $150 / 20 \mathrm{~h}$ & $100^{c}$ & 5 & $-^{\mathrm{e}}$ & $-^{\mathrm{e}}$ & 56 \\
\hline 6 & 3600 & 2.7 & $\mathrm{CH}_{3} \mathrm{O}\left(\mathrm{CH}_{2}\right)_{2} \mathrm{O}^{-} \mathrm{Na}^{+}[15]$ & $\mathrm{CH}_{3} \mathrm{O}\left(\mathrm{CH}_{2}\right)_{2} \mathrm{OH}$ & $100 / 7 \mathrm{~d}$ & $100^{\mathrm{d}}$ & 6 & $\mathrm{f}^{\mathrm{f}}$ & $-^{f}$ & $\cdots$ \\
\hline 7 & 3100 & 2.8 & $\mathrm{BF}_{3} \cdot \mathrm{OEt}_{2}[0.48]$ & $\mathrm{CHCl}_{3}$ & $0 / 1 \mathrm{~min}$ & $100^{\mathrm{d}}$ & 7 & ${ }^{\mathrm{f}}$ & $\mathrm{f}^{\mathrm{f}}$ & - \\
\hline
\end{tabular}

${ }^{\mathrm{a}}$ Determined by GPC. Eluent: THF. Polystyrene was used as the standard for calibration. ${ }^{\mathrm{b}}$ Determined from onset of $T_{\mathrm{g}}$ peak in DSC. ${ }^{\mathrm{c}}$ Determined by ${ }^{1} \mathrm{H}$ NMR spectrum. ${ }^{\mathrm{d}}$ Determined by IR spectrum. ${ }^{\mathrm{e}}$ No peak was observed in GPC measurement. ${ }^{\mathrm{f}}$ Cannot be measured due to insolubility of the obtained polymer.

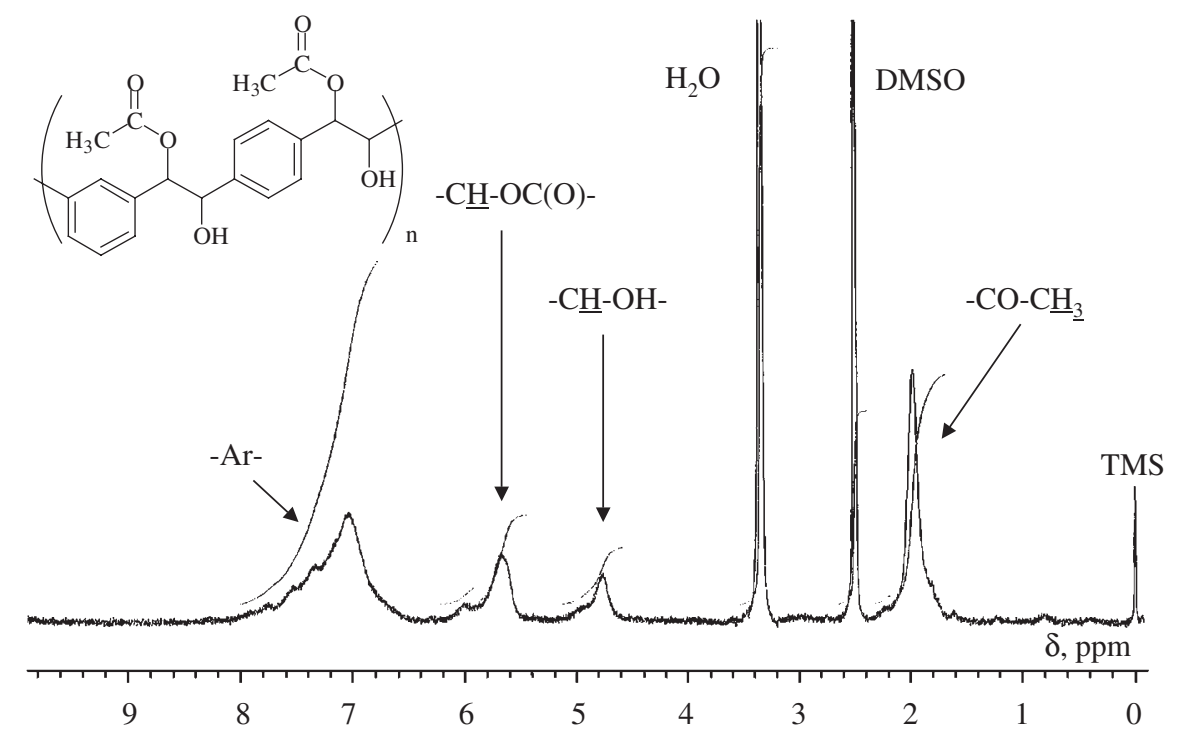

Figure 4. ${ }^{1} \mathrm{H}$ NMR spectrum of polymer 3 in DMSO- $d_{6}$. 


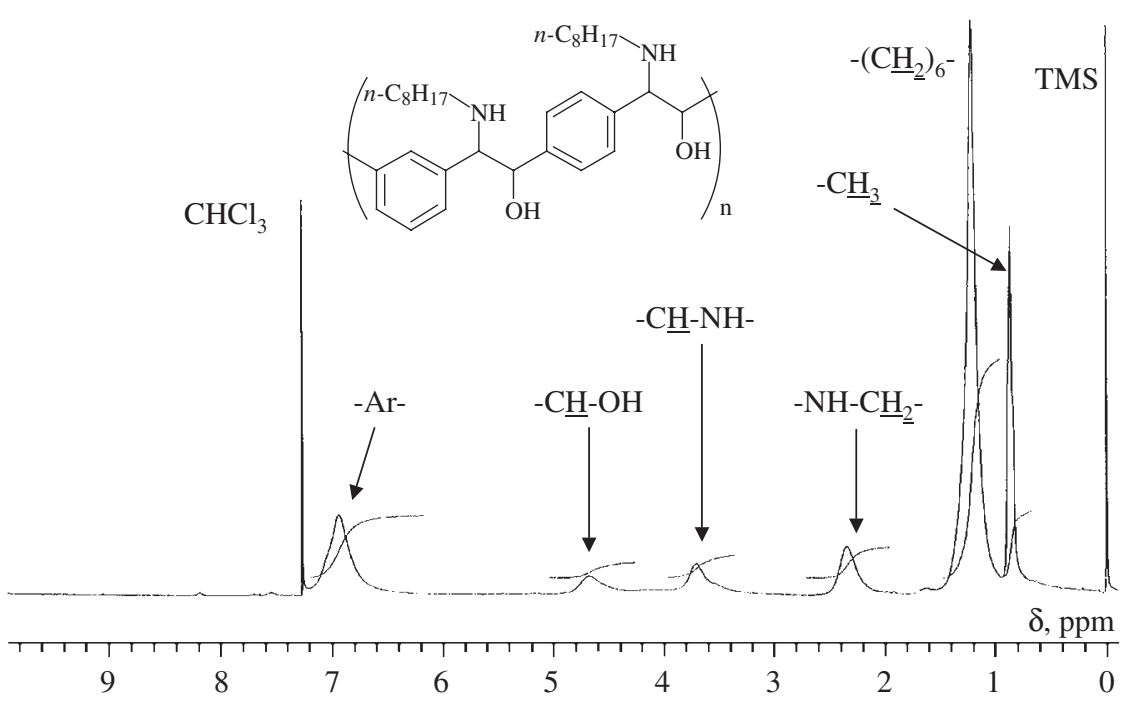

Figure 5. ${ }^{1} \mathrm{H}$ NMR spectrum of polymer 5 in $\mathrm{CDCl}_{3}$.

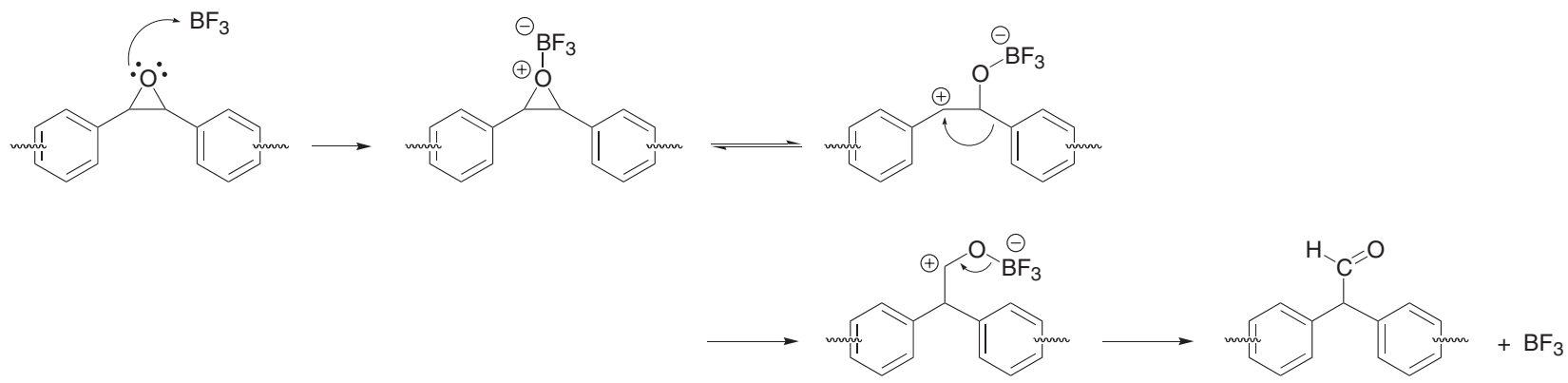

Scheme 4.

of the polymer would be negligible because increased flexibility of the polymer $\mathbf{4}$ is considered to affect the value of the molecular weights measured by GPC, which is known to be influenced by flexibility of the polymer main chain. $T_{\mathrm{g}}$ of $\mathbf{4}$ was observed at $81{ }^{\circ} \mathrm{C}$ in DSC measurements and was lower than $T_{\mathrm{g}}$ of $\mathbf{3}$.

As shown in run 4 of Table IV, the reaction of $m, p$ PPVO with 20 equivalents of $n$-octylamine in refluxing 1,4-dioxane (bp $102^{\circ} \mathrm{C}$ ) opened $17 \%$ of the oxirane rings. By changing the solvent from 1,4-dioxane to DMSO and heating the system at $150^{\circ} \mathrm{C}$ for $20 \mathrm{~h}$, the polymer 5 having $\mathrm{OH}$ and $n-\mathrm{C}_{8} \mathrm{H}_{17} \mathrm{NH}$ groups with complete conversion of the oxirane rings was obtained (run 5, Scheme 3). Ring-opening of oxirane was confirmed by the disappearance of the peak at $4.1 \mathrm{ppm}$ (see Figure 1) and the appearance of peaks at 3.7 and $4.7 \mathrm{ppm}$ in the ${ }^{1} \mathrm{H}$ NMR spectrum of $\mathbf{5}$ (Figure 5). The glass transition temperature of $\mathbf{5}$ was observed at $56^{\circ} \mathrm{C}$ in the DSC profile, and the decrease in $T_{\mathrm{g}}$ would be due to $n$-octyl side chains in $\mathbf{5}$.

Nucleophilic ring-opening reaction of the oxirane rings in $m, p$-PPVO with sodium 2-methoxyethoxide was examined in run 6 of Table IV. The product from the reaction at $100^{\circ} \mathrm{C}$ for $7 \mathrm{~d}$ showed no absorption derived from the oxirane rings in the IR spectrum and this indicates the formation of the polymer $\mathbf{6}$ with $\mathrm{OH}$ and $\mathrm{OCH}_{2} \mathrm{CH}_{2} \mathrm{OCH}_{3}$ groups (Scheme 3). However, insolubility of $\mathbf{6}$ in any solvent prevented further identification: this polymer may contain crosslinked structures produced by anionic polymerization of the oxirane in the main chain.

The pinacol rearrangement of the oxirane rings in $m, p$-PPVO was carried out by using $\mathrm{BF}_{3} \cdot \mathrm{OEt}_{2}$ as a catalyst (run 7). The reaction of $m, p$-PPVO with $\mathrm{BF}_{3} \cdot \mathrm{OEt}_{2}$ for $1 \mathrm{~min}$ afforded the polymer 7 with $\mathrm{CHO}$ groups, whose IR spectrum shows $\mathrm{C}=\mathrm{O}$ stretching absorption derived from aldehyde $\left(1720 \mathrm{~cm}^{-1}\right)$ but does not show the absorption due to oxirane rings at $835 \mathrm{~cm}^{-1}$ (Figure 3). The plausible mechanism for the pinacol rearrangement of $m, p$-PPVO with $\mathrm{BF}_{3} \cdot \mathrm{OEt}_{2}$ is exhibited in Scheme 4. However, 7 was not soluble in any solvent, probably due to crosslinking of the polymer by ring-opening cationic polymerization of the oxirane groups and/or interchain aryl transfer during the rearrangement.

\section{Solubility of the Polymers}

Solubility of $p$-PPVO, $m, p$-PPVO, $m$-PPVO, and 
Table V. Solubility of PPVOs and the polymers obtained by the polymer reactions (3-7)

\begin{tabular}{ccccccc}
\hline Polymer & $\mathrm{CH}_{3} \mathrm{OH}$ & $\mathrm{DMSO}$ & Acetone & $\mathrm{THF}$ & $\mathrm{CHCl}_{3}$ & $\left(\mathrm{CH}_{3} \mathrm{CH}_{2}\right)_{2} \mathrm{O}$ \\
\hline$p$-PPVO & $\mathrm{I}$ & $\mathrm{I}$ & $\mathrm{I}$ & $\mathrm{I}$ & $\mathrm{I}$ & $\mathrm{I}$ \\
$m$-PPVO & $\mathrm{I}$ & $\mathrm{S}$ & $\mathrm{I}$ & $\mathrm{S}$ & $\mathrm{S}$ & $\mathrm{I}$ \\
$m, p$-PPVO & $\mathrm{I}$ & $\mathrm{S}$ & $\mathrm{I}$ & $\mathrm{S}$ & $\mathrm{S}$ & $\mathrm{I}$ \\
$\mathbf{3}$ & $\mathrm{I}$ & $\mathrm{S}$ & $\mathrm{S}$ & $\mathrm{S}$ & $\mathrm{S}$ & $\mathrm{I}$ \\
$\mathbf{4}$ & $\mathrm{S}$ & $\mathrm{S}$ & $\mathrm{P}$ & $\mathrm{S}$ & $\mathrm{S}$ & $\mathrm{I}$ \\
$\mathbf{5}$ & $\mathrm{I}$ & $\mathrm{S}$ & $\mathrm{I}$ & $\mathrm{S}$ & $\mathrm{S}$ & $\mathrm{S}$ \\
$\mathbf{6}$ & $\mathrm{I}$ & $\mathrm{I}$ & $\mathrm{I}$ & $\mathrm{I}$ & $\mathrm{I}$ & $\mathrm{I}$ \\
$\mathbf{7}$ & $\mathrm{I}$ & $\mathrm{I}$ & $\mathrm{I}$ & $\mathrm{I}$ & $\mathrm{I}$ & $\mathrm{I}$ \\
\hline
\end{tabular}

S: soluble, P: partially soluble, I: insoluble

the polymers 3-7 in various solvents are summarized in Table V. Though $p$-PPVO was insoluble in any solvent, no difference in solubility between $m, p$-PPVO and $m$-PPVO was observed. Introduction of acetoxy groups onto the polymer main chain made the polymer 3 soluble in acetone. The polymer reaction of $m, p$-PPVO with LAH gave the polymer $\mathbf{4}$ having $\mathrm{OH}$ groups in the main chain and this polymer became soluble in methanol. The polymer 5 having $n$-octylamino groups acquired solubility in diethyl ether. These results indicate that properties of PPVOs can be adjusted by polymer reactions with various reagents and that PPVOs are available as novel reactive polymers.

\section{CONCLUSIONS}

PPVOs having oxirane groups in the main chain were obtained by polycondensation using the CoreyChaykovsky reaction between bis(sulfonium ylide)s and dialdehydes. The sulfonium ylides were prepared in situ from xylylenebis(dimethylsulfonium perchlorate)s by using dimsyl anion or LDA as a base. The reaction of a bis(sulfonium ylide), prepared from $m$-xylylenebis(dimethylsulfonium perchlorate) 2 and LDA, with terephthalaldehyde afforded $m, p$-PPVO with $M_{\mathrm{n}}=3600$. Polymer reactions of $m, p$-PPVO with acetic acid, LAH, $n$-octylamine, sodium 2-methoxyethoxide and $\mathrm{BF}_{3} \cdot \mathrm{OEt}_{2}$ gave the corresponding ring-opening products. The resulting polymers showed the properties reflecting the structure of the reagents used in the polymer reactions, and therefore, PPVOs are considered as novel reactive polymers whose properties can easily be adjusted by polymer reactions.

\section{REFERENCES}

1. a) W. R. Ashcroft, in "Chemistry and Technology of Epoxy Resins,” B. Ellis, Ed., Blackie A \& P, London, U.K., 1993, chapt. 2. b) M. Fujiwara, M. Imada, A. Baba, and H. Matsuda, Tetrahedron Lett., 30, 739 (1989).

c) M. Chini, P. Crotti, and F. Macchia, Tetrahedron Lett., 31, 4661 (1990).

2. M. B. Smith and J. March, "March's Advanced Organic Chemistry," 5th ed., Wiley-Interscience, New York, N.Y., 2001, p 481.

3. a) A. Schaap and J. F. Arens, Recl. Trav. Chim. Pays-Bas, 87, 1249 (1968).

b) C. Huynh, F. Derguini-Boumechal, and G. Linstrumelle, Tetrahedron Lett., 20, 1503 (1979).

4. a) A. Alexakis, E. Vrancken, and P. Mangeney, Synlett, 1998, 1165.

b) B. H. Lipshutz, J. Kozlowski, and R. S. Wilhelm, J. Am. Chem. Soc., 104, 2305 (1982).

c) J. M. Chong and K. B. Sharpless, Tetrahedron Lett., 26, 4683 (1985).

5. a) R. C. Larock, "Comprehensive Organic Transformations," VCH, New York, N.Y., 1989, p 505, and references cited therein.

b) E. F. Healy, J. D. Lewis, and A. B. Minniear, Tetrahedron Lett., 35, 6647 (1994).

6. M. B. Smith and J. March, "March's Advanced Organic Chemistry," 5th ed., Wiley-Interscience, New York, N.Y., 2001, p 1235.

7. F. K. Thayer, C. S. Marvel, and G. S. Hiers, "Organic Syntheses," Coll. Vol. 1; Wiley, New York, N.Y., 1941, p 117.

8. D. J. Reif and H. O. House, "Organic Syntheses," Coll. Vol. 4; Wiley, New York, N.Y., 1963, p 375.

9. Y, Tanaka and R. S. Bauer, in "Epoxy Resins - Chemistry and Technology_," 2nd ed., C. A. May, Ed., Marcel Dekker, New York, N.Y., 1988, chapt. 2-IV.B.

10. a) C. A. May, Ed., "Epoxy Resins - Chemistry and Technology_," 2nd ed., Marcel Dekker, New York, N.Y., 1988. b) B. Ellis, Ed., "Chemistry and Technology of Epoxy Resins," Blackie A \& P, London, U.K., 1993.

11. a) F. Lohse and H. Zweifel, Adv. Polym. Sci., 78, 61 (1986). b) C. Decker, Prog. Polym. Sci., 21, 593 (1996).

c) T. Oyama, T. Yamashita, T. Suzuki, K. Ebitani, M. Hoshino, T. Iijima, and M. Tomoi, React. Funct. Polym., 49, 99 (2001).

12. a) R. C. Larock, "Comprehensive Organic Transformations," VCH, New York, N.Y., 1989, p 456, and references cited therein. 
b) R. D. Bach, C. Canepa, J. E. Winter, and P. E. Blanchette, J. Org. Chem., 62, 5191 (1997).

13. a) A. C. Knipe, J. Chem. Soc., Perkin Trans. 2, 1973, 589.

b) B. Koppenhoefer and V. Schurig, "Organic Syntheses," Coll. Vol. 8, Wiley, New York, N.Y., 1993, p 434.

14. a) E. J. Corey and M. Chaykovsky, J. Am. Chem. Soc., 87, 1353 (1965)

b) V. K. Aggarwal and J. Richardson, Chem. Commun., 2003, 2644.

c) A. Padwa and J. R. Gasdaska, Tetrahedron, 13, 4147 (1988).

d) E. Akgün, M. B. Glinski, K. L. Dhawan, and T. Durst, J. Org. Chem., 46, 2730 (1981).

e) A. Solladié-Cavallo, L. Bouérat, and M. Roje, Tetrahedron Lett., 41, 7309 (2000).

f) G. A. Kraus and I. Kim, Org. Lett., 5, 1191 (2003).

g) X.-S. Fei and J. G. Verkade, Heteroatom Chem., 10, 538
(1999).

15. a) P. Bakó, Á. Szöllõsy, P. Bombicz, and L. Tõke, Synlett, 1997, 291.

b) T. Shioiri, in "Handbook of Phase Transfer Catalysis," Y. Sasson and R. Neumann, Ed., Blackie A \& P, London, U.K., 1997, chapt. 14, p 471.

16. C. D. Gutsche, Org. React., 8, 364 (1954).

17. E. J. Corey and M. Chaykovsky, J. Am. Chem. Soc., 87, 1345 (1965).

18. a) B. Ellis, in "Chemistry and Technology of Epoxy Resins," B. Ellis, Ed., Blackie A \& P, London, U.K. 1993, chapt. 1, p 12 .

b) Y. Tanaka and R. S. Bauer, in "Epoxy Resins - Chemistry and Technology_," 2nd ed., C. A. May, Ed., Marcel Dekker, New York, N.Y., 1988, chapt 2, pp 317-323, and references cited therein. 